\title{
EI Museo Virtual de las Fiestas del Fuego del Pirineo. Un museo en línea a partir del patrimonio inmaterial
}

\section{The Virtual Museum of the Pyrenees Fire Festivals. An online museum based on intangible heritage}

\section{Xavier Roigéa ${ }^{\mathrm{a}}$ Lluís Bellas ${ }^{\mathrm{b}}$ y Virginie Soulier ${ }^{\mathrm{c}}$}

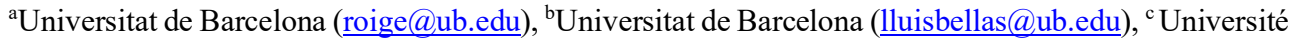
de Perpignan-Via Domitia (virginie.soulier@univ-perp.fr).

\begin{abstract}
Resumen
Este texto presenta el proyecto que estamos desarrollando sobre el Museo Virtual de las Fiestas del Fuego en los Pirineos, inscrita en la Lista Representativa del Patrimonio Inmaterial de la Humanidad. Se trata de un proyecto interfronterizo, desarrollado por distintas universidades y entidades de la administración de España, Francia y Andorra, así como asociaciones dedicadas a la celebración de la fiesta. El proyecto, financiado por fondos Interreg, nació para dar continuidad a la declaración de Patrimonio mundial, pero se ha revelado como una acción necesaria y substitutoria ante la no celebración de las fiestas a causa de la COVID. A través del ejemplo de este proyecto se pretende ir más allá presentando también los retos de los museos virtuales, especialmente de los dedicados al patrimonio inmaterial.
\end{abstract}

Palabras clave: Museo Virtual, Patrimonio Inmaterial, Fiestas del Fuego en los Pirineos, Covid-19, UNESCO

\begin{abstract}
This paper presents the project of the Virtual Museum of the Fire Festivals of the Pyrenees, inscribed on the Representative List of the Intangible Heritage of Humanity. It's a cross-border project, developed by different universities and government entities in Spain, France and Andorra, and different associations dedicated to the celebration of the festivals. The project, financed by Interreg EU funds, was born as a project to give continuity to the declaration of World Heritage, but it has been revealed as a necessary and substitute action before the non-celebration of the Festivals in the Covid periode. Through the example of this project, it's intended to go further, also presenting the challenges of virtual museums, especially those dedicated to intangible heritage.
\end{abstract}

Keywords: Digital Museum, Intangible Heritage, Fire Festivals of the Pyrenees, Covid-19, UNESCO 
El proyecto del Museo Virtual de las Fiestas del Fuego de los Pirineos (Prometheus.Museum) ${ }^{1}$, realizado en marco del Proyecto POCTEFA ${ }^{2}$, pretende difundir estas fiestas mediante exposiciones virtuales, paginas didácticas y recopilación de materiales digitales. El texto se inicia con una reflexión sobre los museos virtuales que tratan del patrimonio inmaterial, presentando diversos ejemplos y sus dificultades de comunicación. A continuación, se presentan los objetivos y el desarrollo del proyecto, indicando los planteamientos técnicos y el proceso mediante el cual se está construyendo el proyecto, que en principio deberá estar operativo en el 2022. A través del ejemplo de este proyecto se pretende ir más allá señalando los retos de los museos virtuales de patrimonio inmaterial.

\footnotetext{
${ }^{1}$ Investigación realizada en el marco de los proyectos: Prometheus de "Las fiestas de fuego de los solsticios de los Pirineos" (EFA309/19) POCTEFA Interreg Fondos Feder; y "Patrimonio Inmaterial y Políticas Culturales: desafíos sociales, políticos y museológicos (PGC2018-096190-B-I00), financiado por el Ministerio de Ciencia, Innovación y Universidades / Agencia Estatal de Investigación / Fondo Europeo de Desarrollo Regional, Unión Europea.

2 Como parte de la financiación internacional europea y del programa Poctefa transfronterizo (entre el 2020 y el 2022 ) el proyecto Prometeus sobre el patrimonio cultural inmaterial de las fiestas del fuego, inscrito en la lista representativa de patrimonio cultural inmaterial de la humanidad de la UNESCO desde 2015. Este proyecto tiene como objetivo fomentar la dinámica del PCI entre Francia, España y Andorra, reforzar la cooperación y la sinergia entre los diferentes actores culturales. Entre las principales acciones del proyecto, que tiene dos años de duración, habrá diversas acciones como el diseño de una aplicación móvil para difundir y aportar valor al patrimonio cultural inmaterial de la humanidad; la investigación y documentación sobre las fiestas; la elaboración de materiales pedagógicos para escuelas, entre otras acciones. El proyecto Prometheus (EFA309/19) está coordinado por la Cátedra de Educación y Patrimonio Inmaterial de los Pirineos (CEPIP) de la Universidad de Lleida (UdL), y cuenta con siete socios más: el Govern d'Andorra, el Departamento de Cultura de la Generalitat de Catalunya, el Conselh Generau d'Aran, el Patronato de Promoción Económica de la Diputació de Lleida, la Universitat de Barcelona, la Université de Perpignan Via-Domitia, el Centre Internacional de Recerca e Documentacion Occitanas (CIRDOC-Institut Occitan de Cultura).
} 


\section{Introducción}

Desde que la UNESCO aprobó en 2003 la Convención para la Salvaguarda del Patrimonio Cultural Inmaterial, definiendo así el concepto de $\mathrm{PCI}^{3}$, se establecieron medidas gubernamentales para la promoción y custodia del patrimonio inmaterial, y los inventarios fueron considerados como un instrumento privilegiado para esa preservación. No es aquí el lugar para discutir los problemas conceptuales del patrimonio inmaterial, ni los problemas metodológicos y teóricos del inventario de elementos intangibles, algo sobre lo que existe una abundante literatura (Bortolotto, 2014; Kirshenblatt-Gimblett, 2004; Kurin, 2004; Roigé, 2014). En todo caso, el planteamiento conceptual holístico de la definición del patrimonio inmaterial viene acompañado generalmente de la realización de inventarios (KirshenblattGimblett, 2004), lo que se traducido en múltiples iniciativas de recopilación de un conjunto de elementos imposibles de inventariar, porque son vivos e infinitos, de naturaleza distinta a los bienes materiales. Tal vez por ello, el valor de los instrumentos digitales para la preservación del PCI tiene ya una larga tradición y las estrategias utilizadas han sido muy variadas (Turgeon y Saint Pierre, 2009).

\subsection{Usos de internet para la salvaguarda del patrimonio inmaterial}

Aunque el mundo digital es un espacio predilecto para la aplicación de Convención de 2003, el PCI es uno de los patrimonios que ha llegado más tarde en la digitalización del patrimonio (MA et al., 2019). En todo caso, el planteamiento de su preservación y divulgación viene directamente relacionado con el uso de tecnologías digitales (Kim et al., 2019). Por definición el PCI es un patrimonio vivo, dinámico y constante recreación por lo que el entorno virtual es un campo a explorar a través de múltiples maneras. Ha habido dos formas básicas de utilización de las nuevas tecnologías para conformar plataformas sobre el PCI: los inventarios y los sitios de memoria. Esta contextualización nos permitirá entender como los museos virtuales pueden ser espacios para recrear, experimentar y salvaguardar el PCI.

\subsubsection{Los inventarios digitales}

El uso de internet como plataforma para el inventario del patrimonio inmaterial ha sido el más frecuente. SOUSA (2017) constata la existencia de 158 inventarios en los 198 países estudiados. La mayoría son bases de datos en línea a partir de los criterios de la Convención, recogiendo listas de prácticas relacionadas con el PCI como fiestas, leyendas, tradiciones orales, o artesanía. Otros se basan en prácticas más participativas, a partir de procedimientos tipo wiki como los de Fatick en Senegal (WikiFatick), de Finlandia (Wiki-inventory of Living Heritage), Escocia (The Inventory of Living Culture) o Corea (Ichpedia). La mayoría de ellos destacan su carácter participativo y la implicación comunitaria, de acuerdo con la convención de la UNESCO. El grado de apertura a la incorporación de los materiales, no obstante, no siempre es absolutamente abierto. Así, el inventario de Escocia se basa en un concepto

\footnotetext{
${ }^{3}$ Para la definición sobre el Patrimonio Cultural Inmaterial, véase https://ich.unesco.org/es/inicio
} 
evolutivo, con grupos de discusión para enriquecer los contenidos, de manera que los miembros de las comunidades pueden modificar sus contenidos, y está diseñado para sensibilizar a las comunidades sobre su patrimonio.

Algunos inventarios van más lejos y se transforman en museos virtuales, incorporando nuevas tecnologías para convertirse en plataformas digitales de consulta con gran accesibilidad a través de interacciones, vídeos, narrativas o geolocalización.

\subsubsection{Los sitios de memoria digitales}

Los sitios planteados como memoria están generalmente basados en recopilaciones de entrevistas o vídeos a personas de las comunidades, presentando narraciones orales sobre sus experiencias en la comunidad, o sus distintas prácticas de PCI. Estos sitios (como el Museu de la Paraula del Museu Valencià d'Etnologia o el Museu da Pessoa, Memoriamedia, The Soundtrack of Our Lives), implican un concepto diferente de PCI, por cuanto pretenden ser bancos de memoria sobre estas prácticas. Una institución de la memoria combina sustitutos digitales de las colecciones de archivos, bibliotecas y museos en un medio interactivo, y permite el acceso a su contenido independientemente de la naturaleza de la institución, conservándolo para futuras generaciones y ofreciendo apoyo para su uso y gestión a lo largo del tiempo (Schweibenz, 2004).

\subsection{Los museos virtuales de PCI}

Hace ya tres décadas que el concepto de museo virtual existe (Schweibenz, 2019). Hoy en día, las nuevas tecnologías nos permiten ir más allá de las paredes de las salas para llegar a nuestras casas superando distintos muros de accesibilidad. Según SCHWEIBENZ (2004) pueden identificarse en internet las siguientes categorías de museos virtuales: el museo catálogo (un sitio web que contiene la información básica acerca del museo, para informar sobre el museo a sus posibles visitantes; el museo de contenido (un sitio que presenta las colecciones del museo e invita al visitante virtual a explorarlas), y el museo virtual (que pretende proporcionar no sólo información sobre la colección, sino crear conexiones digitales). De esta forma, "se crean colecciones digitales que no tienen equivalente en el mundo real. Ésta es la puesta en práctica de la visión de un "museo sin paredes" de André Malraux" (Schweibenz, 2004).

Pero más allá de los museos virtuales relacionados directamente con los museos físicos, nos encontramos con los "museos virtual autónomos" con exposiciones sólo en la red, y que, por lo tanto, se han construido al margen de un museo físico. En algunos casos, pueden seguir un modelo de diseño similar al del museo físico, con paseos virtuales por un museo virtual, o pueden seguir un lenguaje diferente, contemplado con diferentes técnicas que permiten una mayor interacción con el usuario. En esta misma línea, los museos en línea de patrimonio inmaterial van incluso más allá, al conjuntar los lenguajes de los inventarios y sitios de memoria con el formato expositivo de los museos virtuales. Algunos están concebidos como forma de difundir el patrimonio inmaterial o bien como experiencias inmersitas, o incluso como recopilación de narrativas. Las posibilidades de las aplicaciones tecnológicas abren 
nuevas puertas al verdadero reto de estos museos: ¿cómo hacer posible revivir la experiencia de la fiesta en vivo?

\subsubsection{Aproximación a los Museos Virtuales de PCI. Algunos ejemplos}

Para entender los retos que plantean los museos virtuales y las nuevas tecnologías aplicadas al patrimonio inmaterial veremos cuatro ejemplos de museos virtuales de PCI.

El Museo de Carnaval de Suabia (Virtuelles-Fastnachtsmuseum) ${ }^{4}$ es un proyecto estatal de la unión de dos museos de carnaval físicos para representar todos los carnavales de la región y a nivel europeo. Se trata de una plataforma interactiva con diferentes secciones y niveles de consulta e interacción: narración con exposiciones, audiovisuales y textos que se actualizan desde la invención del Carnaval, estructuras rituales, espacio para escuchar y descargar la música de la fiesta, foro de debate e interacción con el público y festeros, e incorpora enlaces a museos del Carnaval de la región, de toda Alemania y Europa. El diseño es atractivo para el usuario e incluye números recursos audiovisuales, textuales y sonoros.

Digital Museums Canada ${ }^{5}$ (antes conocido como Virtual Museums of Canada) es un programa del gobierno federal creado en 2001 para promover museos virtuales en colaboración con instituciones patrimoniales del país. El programa ayuda a desarrollar económica y técnicamente capacidades digitales para compartir historias y experiencias de las sociedades (arte, música, naturaleza, arqueología, patrimonio inmaterial, ...). Entre los centenares de contenidos digitales encontramos un destacado Museo de la primera nación

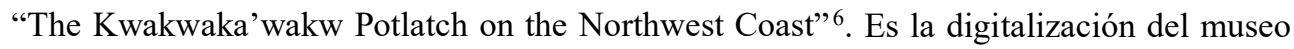
físico U'Mista Cultural Center que amplia online sus contenidos con experiencias inmersivas, tour virtual por la colección, objetos en $3 \mathrm{D}$ y materiales educativos.

Otro ejemplo es la plataforma web de la Patum de Berga ${ }^{7}$, fiesta inscrita como Patrimonio Inmaterial de la Humanidad en 2005. En ella encontramos información básica de la fiesta anual así como dos exposiciones virtuales. La primera cumple la función de presentar de forma general la misma fiesta (colectivos, historia, elementos festivos, rituales). La segunda, "Sons de Patum", es una plataforma con narración sonora interactiva donde el publico recorre la fiesta a través de los sonidos grabados in situ y la contextualización de textos e imágenes.

Para concluir, nos parece interesante el Gion Festival Digital Museum 8 (Kyoto, Japón). Este Museo Virtual se crea en 2020 como reacción ante la suspensión por Covid19 de la Gion Matsuri, una de las fiestas más importantes del Japón e inscrita en la Lista Representativa de Patrimonio Cultural Inmaterial de la UNESCO en 2009. Este museo virtual es producto de los proyectos de digitalización de la fiesta que viene desarrollando desde 1998 el Art Research Center Ritsumeikan. La plataforma reúne recursos digitales como mapas de las

\footnotetext{
${ }^{4}$ Web del Proyecto: https://www.museum4punkt0.de/ergebnis/m4-virtuelles-fastnachtsmuseum/

${ }^{5}$ Web de la plataforma: https://www.digitalmuseums.ca/

${ }^{6}$ Web del museo virtual: https://umistapotlatch.ca/intro-eng.php

${ }^{7}$ Web de la Patum de Berga: http://www.lapatum.cat/

${ }^{8}$ Web del museo virtual: $\underline{\text { https://www.arc.ritsumei.ac.jp/lib/vm/gionfestivalDMe/ }}$
} 
procesiones y rituales en realidad aumentada en 2D y 3D, colección online de objetos, fotografías y documentos o tours virtuales interactivos por los edificios de la fiesta (Li et al., 2020).

\subsubsection{Los recursos de mediación de los museos virtuales de PCI}

Los avances en las tecnologías de digitalización del PCI nos permiten utilizar una gran diversidad de recursos de mediación en los museos virtuales de PCI (Kim et al., 2019). El dinamismo, la recreación y la participación que caracterizan esta tipología de patrimonio plantean un reto al materializar digitalmente los contenidos. Los recursos museográficos se basan principalmente en el uso de diversos medios y tecnologías (sonidos, audiovisuales, hipertexto, realidad aumentada, redes sociales), con el fin de transmitir la vivacidad de los elementos de patrimonio inmaterial y de una manera verdaderamente inmersiva.

Los recursos y estrategias seguidos por estos museos virtuales son diversos, y vamos a tratar de sintetizarlos a partir de distintos ejemplos en el cuadro siguiente:

Tabla 1. Tecnologías y recursos utilizados por museos virtuales de temática PCI

\begin{tabular}{ccc}
\hline Tecnología & Funciones & Ejemplo de uso \\
\hline Experiencia inmersiva & $\begin{array}{c}\text { Entornos virtuales que } \\
\text { generan nuevas realidades }\end{array}$ & $\begin{array}{c}\text { Kawkwaka'wakw Potlatch } \\
\text { (Digital Museums Canada) }\end{array}$ \\
\hline Audio, imagen y vídeo & Reproducción audiovisual & $\begin{array}{c}\text { Sons de Patum. Patrimoni } \\
\text { Sonor de la Patum de Berga }\end{array}$ \\
\hline Vídeo 360 & $\begin{array}{c}\text { Audiovisual en formato } \\
360^{\circ}\end{array}$ & $\begin{array}{c}\text { Hanging out (Digital } \\
\text { Museums Canada) }\end{array}$ \\
\hline Realidad Aumentada & $\begin{array}{c}\text { Interacción con elementos } \\
\text { virtuales en 3D }\end{array}$ & Google Arts Project \\
\hline Cartografia interactiva & $\begin{array}{c}\text { Mapa digital con diferentes } \\
\text { niveles de información }\end{array}$ & Prometheus Museum \\
\hline Contenido co-creado & $\begin{array}{c}\text { Contenido en interacción } \\
\text { con usuarios en web y redes }\end{array}$ & Museu da Pessoa \\
\hline Gamificación & $\begin{array}{c}\text { Técnicas de aprendizaje } \\
\text { basadas en el juego }\end{array}$ & Acropolis Museum Kids \\
\hline
\end{tabular}

Fuente: elaboración propia

Los tipos de tecnologías y que recursos que encontramos en los museos virtuales son muy distintas, desde simples registros sonoros y vídeos hasta tecnologías más sofisticadas, como vídeos en $360^{\circ}$, gamificación, realidad aumentada, experiencias inmersivas, mapas interactivos, simulación del desplazamiento de objetos, presentaciones de imágenes o vídeos con secuencias predeterminadas, posibilidad de creación de contenidos en interacción con los usuarios, museos en directo e inventarios. 
El uso de estas tecnologías da lugar a diferentes tipos de museos virtuales, en función de las posibilidades y de los objetivos de estos. En todo caso, el diseño de estas páginas web nos permite no solo reconstruir simulaciones para emular la experiencia de la visita física, sino que a través de las herramientas comunicativas es posible iniciar procesos de aprendizaje más amplios (Gaia et al., 2020). No obstante, poco a poco se va superando la idea del museo virtual como un sitio que debe parecerse en lo máximo posible al espacio físico, para encontrar a través de nuevas aplicaciones tecnológicas otros contenidos y otras maneras de ver un museo. Como más diferentes sean los museos virtuales de los físicos, más sentido acaban teniendo, al asociar el lenguaje y las metáforas de lo virtual a los contenidos a transmitir (Chiarenza et al., 2019).

\subsection{3 ¿Los espacios virtuales pueden ser espacios para la participación del PCI?}

Una cuestión fundamental en debate para todos los espacios virtuales es el de la participación social. Las posibilidades de los sitios web para la difusión del patrimonio inmaterial es aún un elemento discutido y la idea de participación, para algunos autores, está relacionada con el imaginario del sitio web (Becuywe, 2020). Para Duvelle (2014), internet es un buen útil documental, pero no lo es para la preservación del patrimonio inmaterial. Para esta autora, sería sobre todo un instrumento para la difusión y la sensibilización sobre el PCI, pero no para su preservación y transmisión social, algo que las páginas web o los museos virtuales no podrían asegurar. Por otra parte, surge también un tema que tiene que ver más bien con el propio concepto de inventario en PCI: ¿verdaderamente los inventarios en línea son útiles?

El espacio virtual parece abrir para el PCI nuevas posibilidades de participación, mediante mecanismos que permiten que las comunidades compartan contenidos a través de la redes o museos virtuales. Como señala Severo (2011), la interactividad de los inventarios en línea permite por una parte una interactividad técnica del sitio web, y por otra parte abre las posibilidades a la participación de las comunidades. De hecho, la articulación de estos contenidos en forma de museos virtuales, parten de una lógica distinta en la que el espacio web no es tanto un sitio de acumulación de materiales a la manera documental, sino un espacio de difusión, divulgación, participación y debate social. Se trata, en definitiva, de implantar la misma lógica de los museos participativos y comunicativos al espacio web. Los sitios web abren la posibilidad de crear exposiciones bidireccionales, es decir, con sitios que podrán construirse mediante aportaciones del público que pueden donar materiales e incluso como mecanismo de recolección objetos.

Pero a pesar de estas posibilidades, muchas veces los museos virtuales no explotan esta potencialidad creativa y siguen siendo unidireccionales, no atreviéndose -ya sea por razones políticas, de cultura museística o de dificultades técnicas- a crear espacios verdaderamente abiertos o manipulables como los usuarios, al estilo Wiki (Soulier y Feyssinet, 2020. ¿Puede considerarse entonces que la verdadera participación es una utopía? (Appiotti i Sandri, 2020).

\section{Objetivos y características del proyecto}

Las fiestas del fuego del los Pirineos, que se celebran todos los años en numerosos pueblos del Pirineo, generalmente en la noche de San Juan (23 a 24 de junio) están inscritas en la 
Lista Representativa del PCI en 2015 por Andorra, España y Francia. Las fiestas tienen un significado muy importante para las comunidades locales, y son uno de los elementos más característicos del patrimonio pirenaico (Guil, 2020). La candidatura, presentada por el Gobierno de Andorra, unió a 63 poblaciones de Cataluña, Aragón, Andorra y Occitania que celebran estas fiestas. Aunque las formas de celebración son distintas, las celebraciones más frecuentes consisten en bajar de antorchas encendidas desde las cumbres de las montañas o bien prender fuego a una hoguera en la plaza del pueblo. Para los pueblos que la celebran, las festividades son un acontecimiento de especial importancia, una ocasión para regenerar los vínculos sociales y fortalecer los sentimientos de pertenencia, identidad y continuidad de las comunidades.

La creación de un museo virtual sobre estas fiestas tiene ocho grandes objetivos:

1) Crear una plataforma para contribuir a la presentación de las fiestas, contribuyendo al conocimiento de los distintos sitios donde se celebra.

2) Documentar etnográficamente las fiestas del fuego. Crear un espacio de documentación, recogiendo materiales gráficos y audiovisuales, documentos, y entrevistas con personas de las comunidades.

3) Colaboración entre los diferentes sectores implicados, contribuyendo a que las entidades y asociaciones fallaires puedan colaborar a través de esta plataforma digital.

4) Realizar exposiciones virtuales de carácter general, local o regional.

5) Difundir materiales didácticos. Promocionar y divulgar materiales creados por el propio proyecto y, sobre todo, ofrecer recursos en red.

6) Promover una participación social, a través de una interacción con los usuarios con el uso de las redes sociales y un nuevo concepto de museo "wiki" en el que los usuarios puedan aportar colecciones, experiencias, historias y contenidos.

7) Proporcionar a las comunidades un mecanismo evolutivo para valorar y transmitir su patrimonio.

8) Proponer un mecanismo inclusivo y participativo que aborde y reconozca a cada comunidad a nivel local, pero también, con una proyección internacional. 


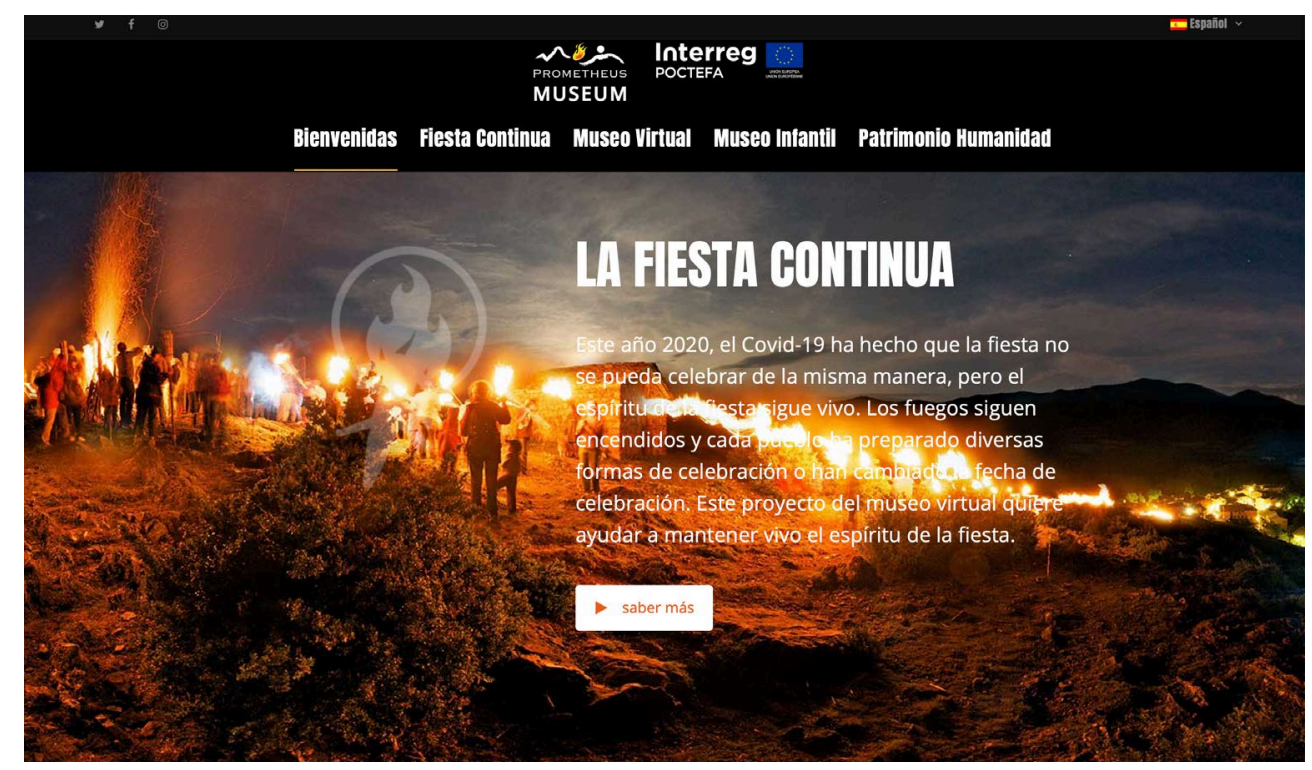

Fuente: Captura de pantalla

Fig. 1. Página de entrada del Museo Virtual Prometheus en la versión preliminar

\section{Desarrollo y características del proyecto}

El sitio web que acogerá este museo virtual pretende ser una entidad específica, no adjunta a un museo físico. Se concibe como un espacio para la comunicación transfronteriza y multilingüe (catalán, francés, español, occitano e inglés). El modelo de este museo es original e innovador, tanto por su misión como por su carácter participativo. El sitio pretende llegar a un gran número de visitantes sin restricciones fronterizas y de movilidad, y crear nuevas comunidades de usuarios. El museo está pensado siguiendo la doble tradición museológica de los museos de etnología y de sociedad, y también siguiendo las nuevas museologías que son a la vez participativas, sociales y relacionadas con un territorio. 


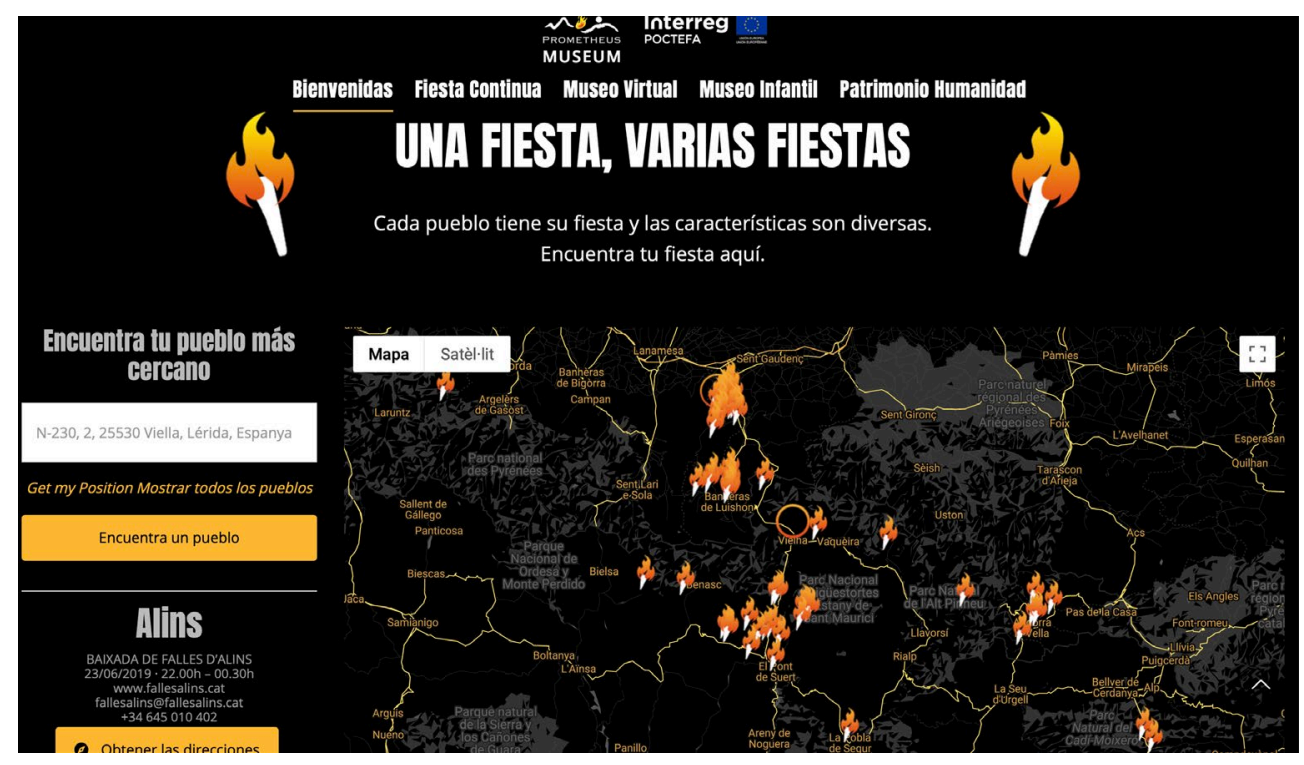

Fuente: Captura de pantalla

Fig. 2. Mapa interactivo (versión preliminar)

\subsection{Públicos a quien se dirige}

Desde una perspectiva democrática, el museo debe ser considerado para un público amplio y diferentes tipos de audiencias. La principal ventaja de un museo digital es su accesibilidad en el tiempo y el espacio, llegando a los no públicos, públicos alejados o con dificultades. Otros activos también vinculados al potencial de lo digital son el enfoqueinmersivo para vivir una experiencia cognitiva, emocional y corporal.

El museo se dirige a distintos tipos de público, contemplando un patrimonio vivo y comunitario que reúne a un centenar de pueblos a ambos lados de las fronteras. Su misión consiste en dar a conocer las diversas manifestaciones festivas relacionadas con el fuego en los Pirineos, con una idea de museo participativo, reforzando las acciones llevadas a cabo desde las diferentes asociaciones y territorios, de acuerdo con los mismos principios de museología social y de los museos de la sociedad.

Por otra parte, también se pretende generar experiencias de visitas "en vivo" a través de transmisiones directas, previa inscripción, lo que permitrá realizar actividades diversas a través de vídeoconferencia o streaming.

\subsection{Principios comunicativos}

La dimensión virtual debe agregar valor respecto a lo que podría ser un museo físico. No se trata de crear una exposición virtual, ni de un centro de documentación integral, sino de crear un espacio museístico que recoja, estudie, valore y transmita el patrimonio de las fiestas del fuego. El enfoque comunicativo es doble: temático y territorial. El museo ofrecerá varias 
entradas con rutas temáticas, incluyendo un mapa interactivo y herramientas de geolocalización.

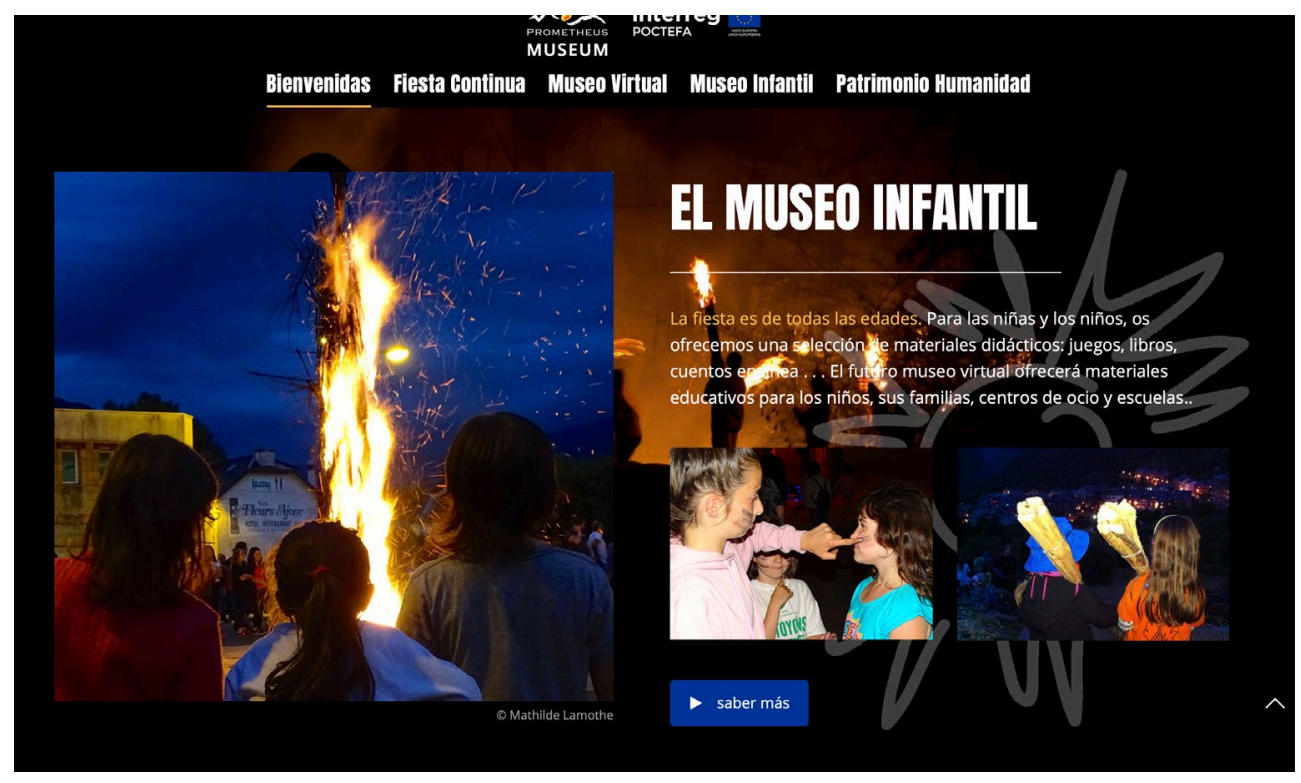

Fuente: Captura de pantalla

Fig. 3. Museo Infantil (versión preliminar)

\subsection{Espacios previstos}

El proyecto está diseñado en cuatro espacios que ofrecen diversos itinerarios posibles, estructurándose de la siguiente forma.

En primer lugar, una exposición de referencia, que presentará la fiesta en su conjunto y su significado, pero sobre todo mostrando cómo se vive y cómo la gente de los pueblos pirenaicos se emociona cada año en su celebración. Por esta razón, se dará la voz a sus protagonistas, a las personas de los pueblos y valles. Se hablará del pasado de la fiesta, pero sobre todo de su presente y de cómo ha cambiado.

En segundo lugar, contará con una presentación de la diversidad de las fiestas. Además de un mapa de los pueblos donde se celebran las fiestas, con documentación fotográfica y vídeos, habrá espacios específicos dedicados a exposiciones de las fiestas de diversos pueblos, valles, regiones o países. El espacio se realizará a partir de un mapa interactivo, con un enlace con las mismas.

En tercer lugar, como en cualquier museo, exposiciones temporales que se irán renovando. Se contemplan de dos tipos: exposiciones temáticas generales, tanto "tradicionales" como nuevos aspectos que permiten destacar su carácter contemporáneo y renovador; y exposiciones territoriales (locales, regionales, nacionales). 
En cuarto lugar, un espacio educativo. Contendrá recursos educativos, cuentos virtuales, material pedagógico, y maletas didácticas. La plataforma en línea podría permitir trabajar en colaboración con diferentes escuelas.

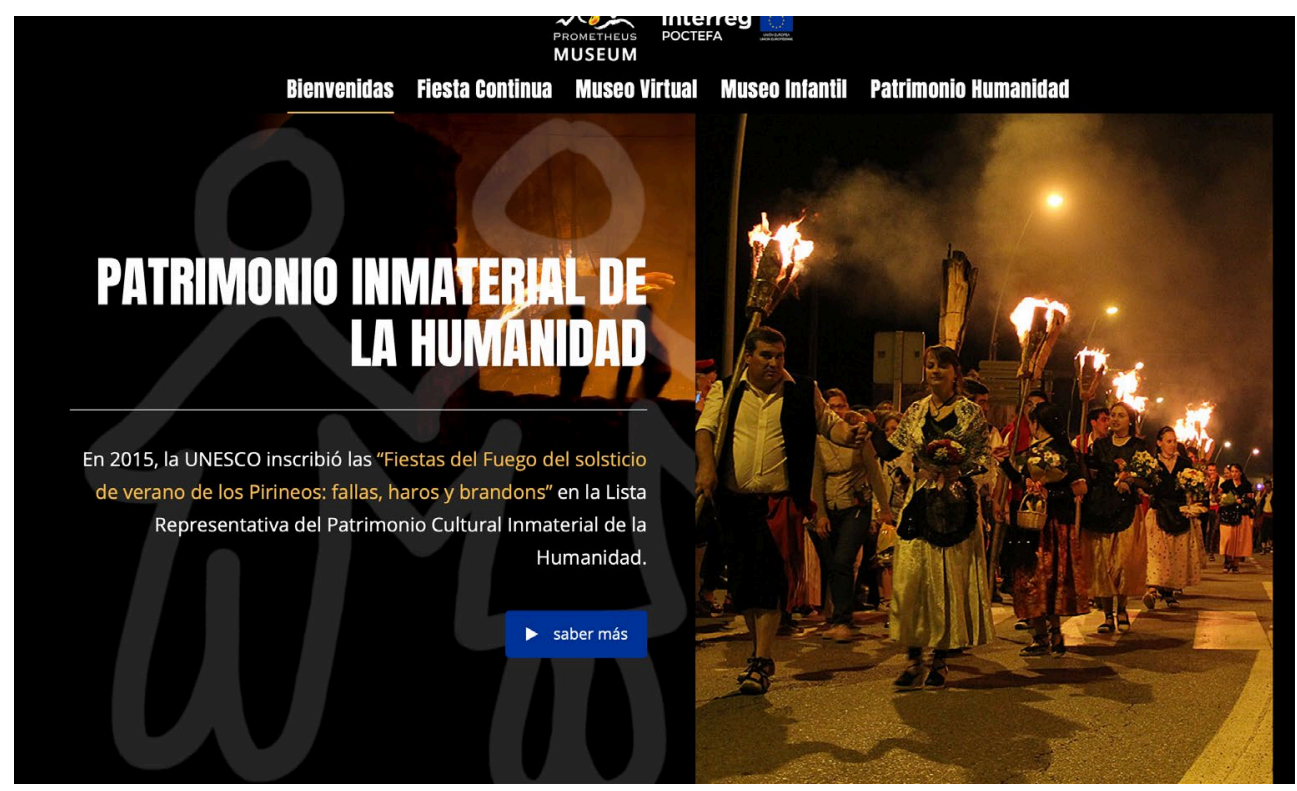

Fuente: Captura de pantalla

Fig. 4. Patrimonio de la Humanidad (versión preliminar)

\subsection{Características técnicas}

El futuro museo seguirá las características que ya se han realizado en una primera edición provisional, enriqueciéndose mediante un enfoque participativo, inclusivo y escalable.

Algunas de las características principales son las siguientes:

- Aplicación web progresiva. Multi-soporte / sensible a la web. Adaptación automática del sitio web a diferentes resoluciones y dispositivos.

- Contenido preparado para una interoperabilidad garantizada.

- $\quad$ Base de datos con medios indexados.

- Los miembros y grupos pueden agregar audio, fotos y videos en forma de wiki

- Mensajería privada entre miembros.

- Moderación por parte del administrador.

- Presentación de algunos objetos en 3D.

- Posibilidades de vídeos inmersivos a 360o. Los servidores deben adaptarse a este tipo de vídeo.

- Enfoque estandarizado para la recolección de materiales. 
- Usabilidad, priorizando la experiencia del usuario.

- Sitios web seductores, visualmente atractivos, y experiencias de navegación fáciles e intuitivas.

- Función de notificación "push" para los visitantes del sitio web

\subsection{Las "colecciones"}

La creación de "nuevas" colecciones es uno de los objetivos de este proyecto. A medida que el museo avance, también pretende crear una "colección" sobre la contemporaneidad de la fiesta a través de acciones de investigación orientadas, que darán lugar a exposiciones temporales.

Cuando hablamos de objetos nos referimos a elementos de diversos tipos, tales como fotografías, videos, postales, recuerdos locales, libros locales, guías, programas y entrevistas. Estos materiales podrán obtenerse a través del propio trabajo documental del museo, pero también a través de donaciones. Mediante la propia plataforma online y las redes sociales habrá campañas para recoger objetos, lo que aumentará las colecciones contemporáneas.

\section{Primeros resultados. Un museo provisional ante la COVID-19}

Aunque el proyecto está previsto para el 2022, la irrupción de la pandemia hizo replantear nuestra planificación, puesto que la mayor parte de las celebraciones festivas previstas para junio de 2020 fueron canceladas. Por ello, se decidió crear un museo virtual de carácter temporal para contribuir, de esta manera a atenuar la no celebración de las prácticas festivas. Para ello, tuvimos que trabajar rápidamente en el enfoque de comunicación para implementar y pensar en los objetivos de acuerdo con la situación y los recursos del momento. En poco más de tres semanas, el museo provisional fue preparado y lanzado para el día de la fiesta. El resultado se configuró como un museo en construcción, como una acción de urgencia. El proyecto se definió indicando que "este año 2020, el Covid-19 ha hecho que la fiesta no se pueda celebrar de la misma manera, pero el espíritu de la fiesta sigue vivo. Los fuegos siguen encendidos y cada pueblo ha preparado diversas formas de celebración. Este proyecto del museo virtual quiere ayudar a mantener vivo el espíritu de la fiesta. De una forma u otra, todos los pueblos mantendrán viva la fiesta, imaginando nuevas formas de celebrarlo, reduciendo el número de asistentes o cambiando la fecha"9.

El sitio web provisional se ha organizado en base a los siguientes apartados:

- $\quad$ Un espacio de bienvenida.

- Un espacio titulado "La fiesta continua", interconectado con las redes sociales, de manera que todos los posts con unos determinados hallstags aparecen automáticamente en el sitio. Esta plataforma social en forma de Social Hub retransmite las actividades de las redes sociales en un flujo continuo a partir de filtros preestableciados.

${ }^{9}$ https://prometheus.museum/es 
- Las características del museo virtual y los espacios del museo

- Un apartado de "Museo infantil" con recursos pedagógicos.

- "Una fiesta, varias fiestas", un mapa en el que se señalan todas las celebraciones.

- Una explicación sobre la fiesta y su inscripción en la UNESCO.

Además, la configuración de Google Analytics permite realizar un seguimiento del uso del sitio.

\section{Conclusiones}

Esta primera experiencia ha permitido, a pesar de su carácter temporal, conocer las posibilidades de un museo virtual sobre el patrimonio inmaterial y sus límites. En el estado actual de su realización se plantean aún problemas a decidir, como su continuidad y la moderación futura del proyecto. Es necesario también asegurar los contindos precisos del proyecto, conceptualizar las modalidades de la recolección de memorias, la captación de imágenes y, sobre todo, contemplar los posibles problemas que la continuación de la pandemia influyan sobre el proyecto. Deberá tenerse en cuenta también la frecuentación y el uso futuro del museo, su gobernanza de acuerdo con las comunidades y la previsión de la obsolescencia de las tecnologías.

En todo caso, el proyecto que hemos definido nos permite cuestionar las oportunidades y posibilidades de los museos virtuales para el patrimonio inmaterial. La situación general de estos museos -a través de los ejemplos presentadps- sugiere sus grandes posibilidades, pero también sus límites. Entre otras cuestiones, y más que limitaciones técnicas, las principales dificultades de los museos de PCI siguen siendo dos: los problemas para encontrar un lenguaje comunicativo específico y definir una verdadera participación social. Al fin y al cabo, los museos virtuales -a pesar de su ya larga historia- son aún muy jóvenes y es necesario aún encontrar soluciones para estos problemas. 


\section{Referencias}

APPIOTTI, S.; SANDRI, E. (2020) "Innovez ! Participez! Interroger la relation entre musée et numérique au travers des injonctions adressées aux professionnels". En : Culture\& Musées, 35, p. 25-48.

BECUYWE, I. (2020) Patrimoine culturel immatériel et technologies numériques: représentations et usages. Quebec: Université Laval. http://hdl.handle.net/20.500.11794/38295

BORTOLOTTO, C. (2014). "La problemática del patrimonio cultural inmaterial”. En: Culturas. Revista de Gestión Cultural, 1(1), p. 1-22. https://doi.org/10.4995/cs.2014.3162

CHIARENZA, S., ACCARDI, A.; INGLISA, R. (2019) "Technological innovación and new estrategias for virtual museum exhibitions". En: ISPRS, XLII-2/W15, 311-318. https://doi.org/10.5194/isprs-archives-XLII-2-W15-311-2019

DEL RÍO CASTRO, J. (2012) “Museos de arte en la red”. En: Telos. Cuadernos de Comunicación e Innovación, (90), p. 61-70.

DUVELLE, C. (2014) "A Decade of Implementation of the Convention for the Safeguarding of the Intangible Cultural Heritage". En : Ethnologies, Revue de l'Association ca- nadienne d'ethnologie et de folklore, 2014, vol. 1-2, no 36, p. 27-46.

EVE MUSEOS (2020) "Breve historia de los museos digitales" https://evemuseografia.com/2020/10/26/breve-historia-de-los-museos-virtuales/ [Consulta: 18 de febrero de 2021]

GUIL, M. (2020) "Patrimonio inmaterial y turismo en los Pirineos: usos sociales y económicos de las fiestas de fuego del solsticio de verano en el Pirineo catalán", En: Congreso AIBR. https://aries.aibr.org/articulo/2019/20/1060/patrimonio-inmaterial-yturismo-en-los-pirineos-usos-sociales-y-economicos-de-las-fiestas-de-fuego-delsolsticio-de-verano-en-el-pirineo-catalan

KIM, S., IM, D., LEE, J.; CHOI, H. (2019) "Utility of Digital Technologies for the Sustainability of Intangible Cultural Heritage (ICH) in Korea”. En: Sustainability, 11(21), 6117. https://doi.org/10.3390/su11216117

KIRSHENBLATT-GIMBLETT, B. (2004) "Intangible heritage as metacultural production" 1. Museum international, 56(1-2), p. 52-65.

KURIN, R. (2004) "Safeguarding Intangible Cultural Heritage in the 2003 UNESCO Convention: a critical appraisal”. En: Museum international, 56(1-2), p. 66-77.

LI, L., HASEGAWA, K., TANAKA, S. (2020) "Recording, Preservation and Exhibition of Objects and Events: An Approach to Digital Museums of Cultural Heritage". En: Journal of the Asia-Japan Research Institute of Ritsumeikan University, 2, p. 166-178. 
MA, X.;TU, L.; XU, Y. (2019) "Development status of the digitization of intangible cultural heritages”. En: Scientia Sinica Informationis, 49(2), p. 121-142. https://doi.org/10.1360/N112018-00201

ROIGE. X (2014) "Més enllà de la UNESCO. Gestionar i museïtzar el patrimoni immaterial". En: Revista d'etnologia de Catalunya, 39, p. 23-40. http://raco.cat/index.php/RevistaEtnologia/article/view/279976/367670

SCHWEIBENZ, W. (2004) "Virtual museums. The Development of Virtual Museums". En ICOM News, $3,3$.

SCHWEIBENZ, W. (2019) "The virtual museum: an overview of its origins, concepts, and terminology". En: The Museum Review, 4(1). http://articles.themuseumreview.org/tmr_vol4no1_schweibenz\%0Ahttps://www.researc hgate.net/publication $/ 335241270$ The virtual_museum_an_overview of its origins_co ncepts and terminology

SEVERO, M. (2011) "Le patrimoine culturel immatériel sur la Toile. Comparaison entre réseaux nationaux". En : Culture et recherche, (125), 50.

SOULIER, V., FREYSSINET, M. (2020). "État des lieux des ressources numériques éducatives et muséales", Patrimoines du Sud, vol. 12.

SOUSA, F. (2017) “MEMORIAMEDIA review - Map of e-Inventories of ICH ». http://review.memoriamedia.net/index.php.

TURGEON, L ; SAINT-PIERRE, L. (2009) "Le patrimoine immatériel religieux au QuébecSauvegarder l'immatériel par le virtuel“. En : Ethnologies, 31, 1, p. 201-233. 